\title{
Physiological effects of vibration in subjects with cystic fibrosis
}

\author{
B. McCarren and J.A. Alison
}

\begin{abstract}
The physiological mechanisms by which vibration and other physiotherapy interventions may clear secretions in subjects with cystic fibrosis are unknown. The main aim of this study was to compare the expiratory flow rates and frequencies of airflow oscillation of vibration to those of Acapella ${ }_{\circledR}$, Flutter ${ }_{\circledR}$, positive expiratory pressure and percussion.

Respiratory flow rates were measured during interventions, the order of which was randomised. The oscillation of the airflow of the interventions was determined by frequency spectral analysis.

In 18 young adult subjects with cystic fibrosis, the mean peak expiratory flow rate of vibration was greater than Flutter ${ }^{\circ}$, percussion, Acapella ${ }_{\otimes}$ and positive expiratory pressure. The mean \pm SD of the oscillation of the airflow of vibration $(8.4 \pm 0.4 \mathrm{~Hz})$ was lower than Acapella ${ }_{\mathbb{B}}(13.5 \pm 1.7 \mathrm{~Hz})$ and Flutter ${ }_{\circledast}(11.3 \pm 1.5 \mathrm{~Hz})$ but similar to percussion $(7.3 \pm 0.3 \mathrm{~Hz})$.

Theoretically, the higher peak expiratory flow rate of vibration compared to the other physiotherapy interventions may promote secretion clearance. In addition, the frequency of oscillation of vibration was within the range demonstrated to increase mucus transport. This study has provided some evidence for the physiological rationale for the use of vibration to aid secretion clearance.
\end{abstract}

\section{KEYWORDS: Airway clearance interventions, peak expiratory flow rate, physiotherapy}

$\mathbf{V}$ ibration is a traditional physiotherapy intervention that is used in patients with respiratory disorders. It is the manual application of fine oscillatory movements combined with compression of the patient's chest wall and is commonly used by physiotherapists to assist with secretion clearance [1]. The compression and oscillation applied during vibration are proposed to aid secretion clearance by a number of physiological mechanisms. These include: 1) increasing absolute peak expiratory flow rates (PEFR) to move secretions towards the oropharynx [2];2) improving the expiratory bias of airflow to increase the annular flow of mucus towards the oropharynx, which occurs when the PEFR is $10 \%$ greater than peak inspiratory flow rate (PIFR), i.e. PEFR/PIFR ratio $>1.1$ [3]; 3) increasing mucus transport by decreasing the viscosity of mucus and improving expiratory flow due to the effects of oscillation of airflow at frequencies ranging from $3-17 \mathrm{~Hz}$ [4]; and 4) eliciting spontaneous coughs via the mechanical stimulation of the airways [5].

Other physiotherapy interventions that may aid secretion clearance incorporate positive pressure or oscillation applied either at the mouth or chest wall. These include the manual techniques of

For editorial comments see page 1082. percussion and mechanical devices such as the positive expiratory pressure (PEP) device, Flutter ${ }^{\circledR}$ and Acapella ${ }^{\circledR}$. These physiotherapy interventions are proposed to aid secretion movement to the central airways, from where they can be expectorated by forced expiratory manoeuvres. Although physiotherapy has been shown to be more effective for secretion clearance than no intervention, there appears to be no difference between the physiotherapy interventions [6, 7]. In addition, the physiological mechanisms by which many of these physiotherapy interventions aid secretion clearance are unknown. An understanding of physiological mechanisms of these interventions in patients with excessive secretions may aid treatment selection.

Once secretions have reached the central airways, the forced expiratory manoeuvres of cough and huff, which rely on high expiratory flow rates, have been demonstrated to be effective for secretion clearance and sputum expectoration [8-10]. The expiratory flow rates of these forced expiratory manoeuvres in patients with cystic fibrosis (CF) have not been previously reported.

Therefore the main aim of this study in subjects with CF was to compare the physiological effects of vibration to other physiotherapy interventions
AFFILIATIONS

School of Physiotherapy, The University of Sydney, Lidcombe, New South Wales, Australia.

CORRESPONDENCE

B. McCarren

School of Physiotherapy

Faculty of Health Sciences

The University of Sydney

PO Box 170

Lidcombe

NSW 1825

Australia

Fax: 1161293519601

E-mail: B.McCarren@

fhs.usyd.edu.au

Received:

July 182005

Accepted after revision:

January 172006

\section{SUPPORT STATEMENT}

Financial support was provided by the National Health and Medical Research Council (Canberra, Australian Capital Territory, Australia) and the Cumberland Foundation (Gerroa, New South Wales, Australia). 
used for airway clearance and relate these effects to the proposed mechanisms of secretion clearance. A secondary aim was to measure the flow rates of the forced expiratory manoeuvres in patients with $\mathrm{CF}$.

\section{MATERIALS AND METHODS Subjects}

Subjects diagnosed with CF were recruited for the study. The exclusion criteria were the presence of two or more of any of the five signs or symptoms of an acute infection within the previous 2 weeks, i.e. fever $>37.5^{\circ} \mathrm{C}$, acute increase in secretion production, increase in shortness of breath, feeling unwell and an increased use of antibiotics.

\section{Procedure}

All testing was carried out during one session. The subjects were asked to refrain from performing any respiratory physiotherapy treatment and taking hypertonic saline or pulmonzyme for $\geqslant 4 \mathrm{~h}$ prior to the study [11]. In addition, subjects were asked not to take any other medication (bronchodilators, etc.) that they would routinely take prior to respiratory physiotherapy. Such medication was administered $15 \mathrm{~min}$ prior to dynamic spirometry (Vitalograph Compact; Vitalograph Ltd, Buckingham, UK) and the testing session.

All interventions were carried out by the same physiotherapist, who instructed the subjects in the various interventions to ensure their consistent application. Each intervention was implemented to replicate current clinical practice and was applied or performed three times by each subject. The order for all interventions was randomised using a computer-generated list.

The physiotherapy interventions were vibration, percussion, PEP device (hereafter referred to as PEP; Astra Tech, Molndal, Sweden), Flutter VRP1 valve ${ }^{\circledR}$ (hereafter referred to as Flutter ${ }^{\circledR}$; Desitin/Scandipharm VarioRaw SA, Birmingham, AL, USA) and Acapella PEP ${ }_{\circledast}$ therapy DH (hereafter referred to as Acapella ${ }^{\circledR}$; DHD Healthcare, Wampsville, NY, USA). The forced expiratory manoeuvres were voluntary cough and huff from high lung volumes (huffHIGH). The subjects also performed an inspiration to total lung capacity (TLC) followed by passive expiration (TLCrelax) to act as a control manoeuvre to account for the effects of lung recoil on expiratory flow.

Vibration was applied manually to the chest wall during expiration after a slow maximal inspiration described to the subject as a "big" breath in. The subjects were asked not to actively expire. Percussion was applied manually during tidal breathing for $\geqslant 30 \mathrm{~s}$ per application. During both vibration and percussion the position of the subject was side-lying, with the reported most productive side uppermost. If there was no difference in reported sputum production between the left and right lungs, then the side-lying position was randomised. The forces applied to the subject's chest wall during both percussion and vibration were at the greatest tolerated level of comfort.

The breathing manoeuvre during the use of the devices of PEP, Flutter ${ }^{\circledR}$ and Acapella ${ }^{\circledR}$ was an inspiration slightly deeper than a normal tidal breath with an end-inspiratory pause of 2-3 s. Expiration was slightly active but not forceful, lasting for $\sim 5 \mathrm{~s}$. During the use of PEP, the resistor selected was one which allowed a positive expiratory pressure between $15-20 \mathrm{cmH}_{2} \mathrm{O}$ [11] for $5 \mathrm{~s}$ to be achieved by each subject. During the use of Flutter $^{\circledR}$, the device was in almost neutral position (i.e. horizontal) to maximise the oscillation amplitude and to target the mid-frequency range of oscillation of $10-15 \mathrm{~Hz}$ [12]. This mid-frequency range is proposed to have maximal effect on mucus transport $[4,13]$. The Acapella ${ }_{\circledast}$ was used according to manufacturer's recommendations (DHD Healthcare) with the resistance set by adjusting the numerical dial to the minimal level at which each subject could exhale for 3-4 s while feeling the vibratory effects.

During huffHIGH and cough the subjects were instructed to inspire maximally, followed by either a forced expiration with the glottis open for huffHIGH or a cough. For TLCrelax subjects were instructed to inspire to TLC and expire passively.

Subjects were instructed to inspire as slowly as possible for all interventions (except percussion) to maximise an expiratory bias to airflow. They were sitting upright for all of the interventions with the exception of vibration and percussion. Between repetitions of an intervention and between each intervention, subjects were encouraged to rest and perform relaxed tidal breathing until they had returned to the baseline effort of breathing.

Ethical approval for the study was obtained from the Central Sydney Area Health Service Ethics Committee and The University of Sydney's Human Research Ethics Committee (both located in Camperdown, New South Wales, Australia) and informed consent was obtained from each subject.

\section{Measurements}

The inspiratory and expiratory flow rates during all interventions were measured via a mouthpiece with a heated pneumotachograph (Hans Rudolph Model 3813; Hans Rudolph Inc., Kansas City, MO, USA). Flow signals were integrated to provide volume measurements [14]. The devices of PEP, Flutter ${ }^{\circledR}$ and Acapella ${ }^{\circledR}$ were attached to the expiratory port of a two-way non-rebreathing valve (2700 series; Hans Rudolph Inc.), which was connected to the pneumotachograph. This enabled inspiration through the pneumotachograph and expiration through the pneumotachograph and the devices. The pneumotachograph was calibrated and used according to recommended guidelines [15]. Data was collected at a sampling frequency of $100 \mathrm{~Hz}$. The subjects were asked to score perceived breathing effort of each intervention using the modified Borg scale for breathlessness [16]. During each intervention the number of spontaneous coughs elicited was recorded with an audiotape for later analysis.

\section{Data analysis}

The oscillation frequency of the interventions that had a proposed oscillation component (i.e. vibration, percussion, Flutter ${ }_{\circledR}$ and Acapella ${ }_{\circledR}$ ) was determined via frequency spectral analysis (Fourier Transform of the auto-correlation function) [17] of the flow data. Analysis of oscillation frequency of cough and huffHIGH was not performed. After each session the number of spontaneous coughs stimulated during each intervention was recorded from the audiotape.

To calculate sample size, a power analysis was performed on the data of the first 14 subjects, to detect a $25 \%$ difference in 
PEFRs between vibration and one of the other interventions of Flutter ${ }^{\circledR}$, Acapella ${ }^{\circledR}$, percussion or PEP. A sample size of 12 subjects was required for this repeated measure study to have $80 \%$ power with $\alpha$ of 0.05 .

In order to minimise the risk of a type-one error due to too many statistical tests, only the inspiratory volume (VI), PEFR, cough frequency and oscillation frequency of vibration were compared with the other physiotherapy interventions of percussion, PEP, Flutter ${ }^{\circledR}$ and Acapella ${ }^{\circledR}$. An additional analysis, comparing $V \mathrm{I}$ and PEFR of vibration with cough and huffHIGH, was performed. A repeated measures ANOVA and a post hoc Dunnett's test were used. A Friedman ANOVA for repeated measures was used to compare the subject's reported breathing effort during vibration with the physiotherapy interventions of Acapella ${ }^{\circledR}$, Flutter ${ }^{\circledR}$, PEP and percussion as the data were not normally distributed. A one-way ANOVA was used to compare the effect of disease severity on the PEFR of vibration. Disease severity was based on forced expiratory volume in one second (FEV1) \% predicted, where severe lung disease was $\mathrm{FEV} 1 \leqslant 40 \%$ pred, moderate lung disease was FEV1 $>40 \%-\leqslant 70 \%$ pred, mild lung disease was FEV1 $>70 \%-$ $<90 \%$ pred and normal lung function was FEV1 $\geqslant 90 \%$ pred [18]. The results report the mean $\pm \mathrm{SD}$ of the subjects' data and mean \pm SD of means of the triplicate measures of each intervention of each subject. Significance was set at the $\mathrm{p}<0.05$ level.

\section{RESULTS}

\section{Subjects}

A total of 18 subjects (seven female) diagnosed with $\mathrm{CF}$ volunteered for the study. The mean \pm SD age of these subjects was $28.5 \pm 6.2 \mathrm{yrs}$ with a body mass index of $20.8 \pm 2.8 \mathrm{~kg} \cdot \mathrm{m}^{-2}$. The mean FEV1 was $55 \%$ pred, with a FEV1/forced vital capacity ratio of $58 \%$. Six subjects had severe lung disease, eight had a moderate lung disease, one had mild lung disease and three subjects had normal lung function.

\section{Effects of physiotherapy interventions on respiratory flow rates and volumes}

The mean PEFR of vibration was 1.4 times greater than Flutter $_{\circledR} \quad(p=0.002), 1.9$ times greater than percussion $(p<0.001), 2.7$ times greater than Acapella ${ }^{\circledR}(p<0.001)$ and 3.6 times greater than PEP $(\mathrm{p}<0.001$; table 1, fig. 1$)$. Figure 2 shows the time course of expiratory flow of the interventions of

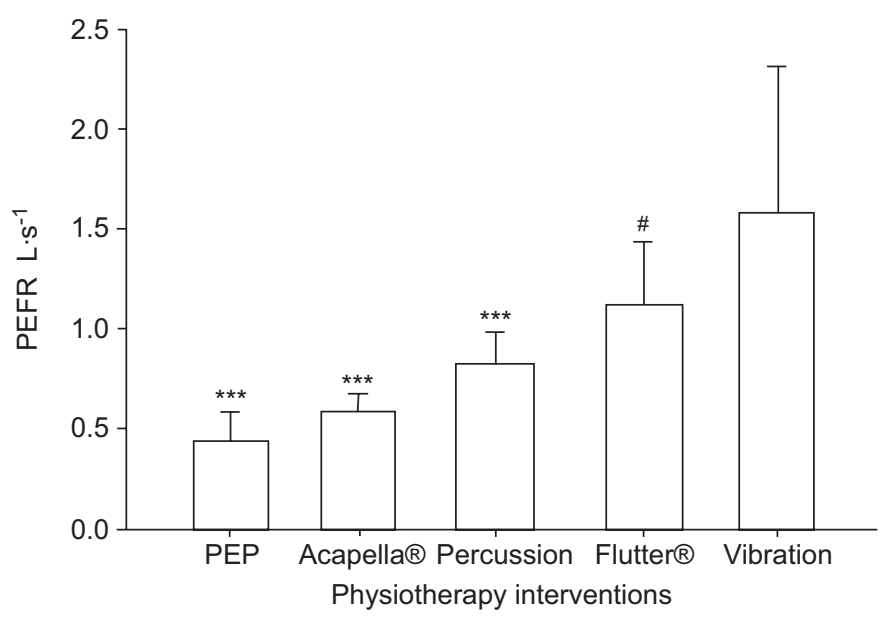

FIGURE 1. The peak expiratory flow rate (PEFR) of physiotherapy interventions. Data are presented as mean \pm SD of means of each subject. PEP: positive expiratory pressure. $p$-values are significantly different from vibration. ${ }^{* * *}: p<0.001$; \# : $p=0.002$.

one subject. There was no significant effect of disease severity on the PEFR of vibration $(p=0.17)$.

There was no significant difference in inspired volumes between vibration and those of PEP, Flutter ${ }_{\circledR}$ and Acapella ${ }_{\circledR}$ (table 1). The inspired volume of vibration was greater than percussion $(\mathrm{p}<0.001)$. There was no difference in the number of coughs stimulated between vibration, percussion, Flutter ${ }^{\circledR}$, Acapella ${ }^{\circledR}$ and PEP $(\mathrm{p}=0.7)$.

\section{Frequency of oscillation of physiotherapy interventions}

Table 2 shows the frequency of oscillation of airflow for vibration, percussion, Flutter ${ }_{\circledR}$ and Acapella ${ }_{\circledR}$.

\section{Forced expiratory manoeuvres}

The mean PEFR of cough and huffHIGH were $2.9(\mathrm{p}<0.001)$ and $3.2(p<0.001)$ times greater than vibration, respectively. The mean inspired volumes of vibration, cough and huffHIGH were similar (table 3).

There were no reported adverse effects during any of the interventions during this study. There was no significant

TABLE 1 Effects of physiotherapy interventions on peak flow rate respiratory volumes and stimulation of cough

\begin{tabular}{|c|c|c|c|c|c|c|c|}
\hline Intervention & Subjects $\mathrm{n}$ & PEFR $L \cdot \mathrm{s}^{-1}$ & PIFR L.s ${ }^{-1}$ & PEFR/PIFR & VI L & VE L & $\begin{array}{c}\text { Coughs } \\
\text { stimulated }\end{array}$ \\
\hline Vibration & $17^{\circ}$ & $1.58 \pm 0.73$ & $1.06 \pm 0.27$ & 1.51 & $1.78 \pm 0.87$ & $2.44 \pm 1.06$ & $0.7 \pm 1.0$ \\
\hline Percussion & 18 & $0.83 \pm 0.14^{\star \star \star}$ & $0.84 \pm 0.10$ & 0.99 & $0.91 \pm 0.37^{\star * \star}$ & $1.03 \pm 0.50$ & $0.5 \pm 0.9$ \\
\hline PEP & 18 & $0.44 \pm 0.15^{\star \star \star}$ & $0.96 \pm 0.20$ & 0.47 & $1.64 \pm 0.40$ & $1.96 \pm 0.57$ & $0.5 \pm 0.6$ \\
\hline Flutter ${ }_{\mathbb{B}}$ & $17^{\circ}$ & $1.13 \pm 0.30^{\#}$ & $1.05 \pm 0.27$ & 1.15 & $1.62 \pm 0.52$ & $1.81 \pm 0.57$ & $0.4 \pm 0.7$ \\
\hline Acapella $_{\mathbb{B}}$ & 18 & $0.59 \pm 0.08^{\star \star \star}$ & $0.98 \pm 0.27$ & 0.64 & $1.55 \pm 0.46$ & $1.68 \pm 0.50$ & $0.8 \pm 1.0$ \\
\hline TLCrelax & $15^{+}$ & $0.66 \pm 0.16$ & $1.01 \pm 0.40$ & 0.73 & $1.79 \pm 0.66$ & $2.24 \pm 0.79$ & 0 \\
\hline
\end{tabular}

Data are presented as mean \pm SD of means of each subject, unless otherwise stated. PEFR: peak expiratory flow rate; PIFR: peak inspiratory flow rate; VI: inspiratory volume; VE: expiratory volume; PEP: peak expiratory pressure; TLCrelax: total lung capacity positive expiration. ${ }^{\bullet}$ : data lost due to technical difficulties (data from different interventions lost in different subjects); ${ }^{+}$: data only collected from stated number of subjects. $p$-values are significantly different from vibration. ${ }^{\star \star \star}: \mathrm{p}<0.001 ;{ }^{*}: \mathrm{p}=0.002$. 


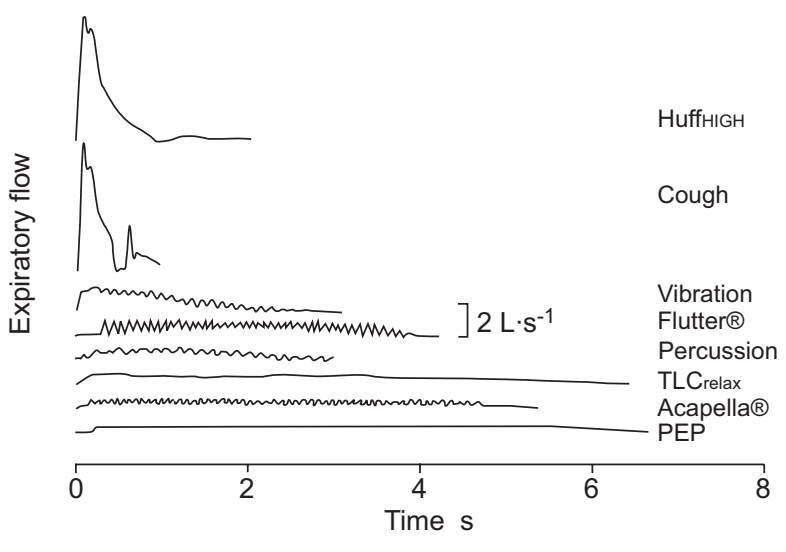

FIGURE 2. The time course of the expiratory flow of the interventions in one subject. The eight traces have been separated vertically for clarity. HuffHIGH: huff from high lung volumes; TLCrelax: total lung capacity passive expiration; PEP: positive expiratory pressure.

\begin{tabular}{ll} 
TABLE 2 & $\begin{array}{l}\text { The frequency of oscillation of the physiotherapy } \\
\text { interventions as determined by frequency } \\
\text { spectral analysis }\end{array}$ \\
& \multicolumn{1}{c}{ Frequency Hz } \\
\hline Intervention & $8.4 \pm 0.4(7.3-10.0)$ \\
\hline Vibration & $7.3 \pm 0.3(6.5-8.0)$ \\
Percussion & $11.3 \pm 1.5(7.5-13.7)^{\star \star *}$ \\
Flutter & $13.5 \pm 1.7(10.0-18.3)^{\star \star *}$ \\
Acapella &
\end{tabular}

Data are presented as mean $\pm S D$ of means of each subject. $p$-value is significantly different from vibration. $* * *: p<0.001$.

difference in the perceived effort between the interventions and no significant effect of the order of the interventions on perceived effort was noted.

\section{DISCUSSION}

This is the first study to report the physiological measures of expiratory flow rates, inspiratory volumes, oscillation frequencies and cough stimulation of vibration and to compare these to other physiotherapy interventions used for secretion clearance in patients with CF. Vibration had greater expiratory flow rates and a higher PEFR/PIFR ratio than the other physiotherapy interventions. However, Flutter ${ }^{\circledR}$ and Acapella ${ }^{\circledR}$ had higher oscillation frequencies than vibration. These data allow inferences to be drawn about the possible effects of the physiotherapy interventions on secretion clearance based on theoretical rationale.

The PEFR of vibration was greater than all the other physiotherapy interventions and than PEFR of TLCrelax. This may be due to the fact that the compressive and oscillatory forces of vibration, applied to the chest wall, may increase intrapleural pressure and might therefore increase expiratory flow rates above those of elastic lung recoil as measured by TLCrelax. In addition, vibration did not have the added resistance at the mouth to impede expiratory flow as occurred during PEP, Acapella ${ }_{\circledR}$ and Flutter ${ }_{\circledR}$. This shows that external forces applied to the chest wall during vibration increase peak expiratory flow rate and thus vibration may be a beneficial intervention for secretion clearance.

The absolute PEFR of vibration was greater than the other physiotherapy interventions. Whether the absolute PEFR of vibration is adequate to clear secretions is not known, as the critical absolute PEFR required for secretion clearance is dependant upon the volume of secretion and the viscoelasticity of the secretions [3, 19-21]. However, vibration had a PEFR/ PIFR ratio $>1.1$, which is the critical level required for annular flow of secretions towards the oropharynx [3]. Therefore, if increasing expiratory flow contributes to the mechanisms for secretion clearance, vibration is likely to be more effective for secretion clearance than the other physiotherapy interventions. The efficacy of vibration for secretion clearance needs to be investigated with radio-aerosol clearance studies [7].

It could be argued that performing all the interventions at the same testing session may have resulted in an order effect in which the performance of an intervention could have altered the expiratory flow of subsequent interventions. To reduce the possibility of this, interventions were performed in a random order and bronchodilators were administered prior to testing to those subjects diagnosed with responsive airways. In addition, subjects did not report any increase in perceived breathing effort, suggesting that fatigue did not occur due to multiple interventions.

The mean number of spontaneous coughs elicited during vibration was less than one and was not significantly different

\begin{tabular}{|c|c|c|c|c|c|c|c|}
\hline TABLE 3 & $\begin{array}{l}\text { Effects of forced e } \\
\text { of coughs }\end{array}$ & ory manoeuvr & mpared t & tion on pe & $\checkmark$ rates res & ory volum & stimulation \\
\hline Intervention & Subjects $n$ & PEFR L.s ${ }^{-1}$ & PIFR L. $\mathbf{s}^{-1}$ & PEFR/PIFR & VI L & VE L & $\begin{array}{l}\text { Coughs } \\
\text { stimulated }\end{array}$ \\
\hline Vibration & $17^{\circ}$ & $1.58 \pm 0.73$ & $1.06 \pm 0.27$ & 1.51 & $1.78 \pm 0.87$ & $2.44 \pm 1.06$ & $0.7 \pm 1.0$ \\
\hline Cough & $17^{\circ}$ & $4.67 \pm 1.91^{* \star *}$ & $1.68 \pm 0.74$ & 3.07 & $1.78 \pm 0.85$ & $2.02 \pm 0.92$ & $1.9 \pm 2.3$ \\
\hline
\end{tabular}

Data are presented as mean \pm SD of means of each subject, unless otherwise stated. PEFR: peak expiratory flow rate; PIFR: peak inspiratory flow rate; V: inspired volume; VE: expired volume; HuffHIGH: huff from high lung volumes. " : data lost due to technical difficulties (data from different interventions lost in different subjects). p-value is significantly different from vibration. ${ }^{* * *}: p<0.001$. 
from the other physiotherapy interventions. These results suggest that stimulation of a cough is not a mechanism by which these physiotherapy interventions may aid secretion clearance.

The interventions of PEP and Acapella ${ }_{\circledR}$ had slower PEFRs compared to vibration. The PEFRs of PEP and Acapella ${ }^{\circledR}$ were 3.6 and 2.7 times slower than vibration, respectively. This was probably due to the fact that the resistance provided by these two devices impeded expiratory flow rates. If the main physiological mechanisms by which secretion clearance is enhanced are a high PEFR and an expiratory bias to airflow, then neither PEP nor Acapella ${ }^{\circledR}$ would be the intervention of choice. However, the results of this study cannot determine whether PEP or Acapella ${ }_{\circledR}$ are ineffective in moving secretions to the central airway. The theoretical rationale of the positive expiratory pressure of these devices is to provide back pressure within the airways during expiration. This increased pressure is proposed to stabilise collapsible airways, thus increasing expiratory flow in these airways [22], and to recruit the collateral ventilation [23] allowing gas behind the secretions, thus aiding the movement of these secretions towards the oropharynx. The results of the current study cannot discount the possibility of this mechanism occurring during PEP or Acapella ${ }^{\circledR}$.

Secretion clearance may be aided by the oscillation of airflow [4]. All the physiotherapy interventions, with the exception of $\mathrm{PEP}$, had an oscillation frequency within the $3-17 \mathrm{~Hz}$ range shown to facilitate mucociliary clearance [4]. These oscillation frequencies may assist secretion clearance by altering rheology of the mucus [4] and increasing ciliary beat through stimulation of the ciliated epithelial cells [24, 25]. The oscillation frequencies of Flutter $(11.3 \mathrm{~Hz})$ and Acapella ${ }_{\circledast}(13.5 \mathrm{~Hz})$ were close to the cited optimal frequency for secretion clearance $(13 \mathrm{~Hz})[4,13]$. The natural frequency of the ciliary beat is 11$15 \mathrm{~Hz}$, and if airflow oscillates at a similar frequency, this resonance may increase the amplitude of the cephalad-ciliary beat, which could in turn increase mucus transport [4]. Flutter ${ }^{\circledR}$ and Acapella ${ }^{\circledR}$ might increase mucus transport with this resonance mechanism. There have been no known previous studies that have reported the oscillation frequencies of these interventions in patients with CF. The oscillation frequencies of all these physiotherapy interventions are within the range demonstrated to improve secretion clearance and therefore provide some evidence for their use during physiotherapy.

This is the only known study to report the expiratory flow rates of cough and huff in patients with CF. The PEFRs of cough $\left(4.67 \mathrm{~L} \cdot \mathrm{s}^{-1}\right)$ and huffHIGH $\left(5.04 \mathrm{~L} \cdot \mathrm{s}^{-1}\right)$ in subjects with $\mathrm{CF}$ are lower than the reported PEFR of these manoeuvres in normal subjects but similar to other subjects with airway obstruction $[26,27]$. The forced expiratory manoeuvres of cough and huffHIGH have been demonstrated to be effective for secretion clearance in patients with chronic obstructive pulmonary disease and bronchiectasis [8-10]. It is not surprising that cough and huffHIGH had a greater PEFR and a higher PEFR/ PIFR ratio than vibration. The results of the current study provide some evidence to support the argument that cough and huff would be effective interventions to assist secretion clearance in patients with CF due to the high expiratory flow rates. However, these forced expiratory manoeuvres do not have the benefit of the oscillation of airflow, which may increase cilial beat or alter the rheology of the secretions to aid secretion clearance. However, it would be interesting to measure the combined physiological effects of vibration applied during the forced expiratory manoeuvres.

The present study's data has provided some evidence to enable inferences to be made about the possible effects of vibration on secretion clearance based on theoretical rationale. Physiotherapists now have some evidence upon which they may base their decision-making for treatment selection, as previous research noted that vibration is widely used in patients with excessive secretions [1]. Recommendations for clinical practice based on these inferences are that cough and huffHIGH may be used to increase PEFR and optimise the PEFR/PIFR ratio, thus aiding secretion clearance by annular flow. If patients with CF are unable to cough or huff effectively (when fatigued, for example) then vibration could be used, as this resulted in the fastest PEFR and highest PEFR/PIFR ratio of the physiotherapy interventions. If patients with CF do not have a carer to apply vibration during airway clearance treatment then Flutter ${ }^{\circledR}$ may be the intervention of choice as the PEFR/PIFR ratio was also $>1.1$. The subjects in this study were encouraged to inspire as slowly as possible to optimise the chances of increasing the expiratory bias to airflow, increasing the likelihood of clearance of secretions by annular flow. Theoretically, if secretions are to be cleared effectively, patients should be encouraged to inspire as slowly as possible.

\section{Limitations}

The principle aim of this study was to measure expiratory flow rates and oscillation frequencies of vibration and other physiotherapy interventions, not to measure the effects of these interventions on secretion clearance. Thus, it was not determined whether the subjects had excessive secretions, nor was secretion clearance measured. However, all subjects performed physiotherapy for airway clearance at least daily, implying that they perceived they had excessive secretions. Secondly, the PEFR does not reflect flow in the peripheral airways from which the physiotherapy interventions are proposed to clear secretions. A measure of interest would have been the maximal expiratory flow rates during the latter half of expiration as an indication of peripheral airflow. However, in order to compare this measure between interventions, the flow rates at similar lung volumes are required. The physiotherapy interventions were performed at different lung volumes, reflecting current clinical practice and thus precluding such a comparison.

\section{Conclusions}

This study provided physiological evidence to suggest that in subjects with cystic fibrosis and stable lung function, vibration may be effective in secretion clearance by assisting with the movement of secretions according to the theoretical rationale of increasing absolute expiratory flow rates, peak expiratory flow rate/peak inspiratory flow rate ratio $>1.1$ and oscillation frequency. The effects of vibration on secretion clearance are still unknown. However, the data from the present study have provided some evidence to enable inferences to be drawn about the possible effects of these physiotherapy interventions on secretion clearance based on theoretical rationale. 


\section{ACKNOWLEDGEMENTS}

The authors wish to thank R. Dentice and C. Moriarty for assistance with subject recruitment.

\section{REFERENCES}

1 McCarren B, Alison JA, Lansbury G. The use of vibration in public hospitals in Australia. Physiother Theory Pract 2003; 19: 87-98.

2 Webber BA, Pryor JA, Bethune DD, Potter HM, McKenzie D. Physiotherapy techniques. In: Pryor JA, Webber BA, eds. Physiotherapy for Respiratory and Cardiac Problems. 2nd Edn. Edinburgh, Churchill Livingstone, 1998; p. 149.

3 Kim CS, Iglesias AJ, Sackner MA. Mucus clearance by twophase gas-liquid flow mechanism: asymmetric periodic flow model. J Appl Physiol 1987; 62: 959-971.

4 King M, Phillips DM, Gross D, Vartian V, Chang HK, Zidulka A. Enhanced tracheal mucus clearance with high frequency chest wall compression. Am Rev Respir Dis 1983; 128: 511-515.

5 Mellins RB. Pulmonary physiotherapy in paediatric age group. Am Rev Respir Dis 1974; 110: 137-142.

6 Thomas J, Cook DJ, Brooks D. Chest physical therapy management of patents with cystic fibrosis. A metaanalysis. Am J Respir Crit Care Med 1995; 151: 846-850.

7 van der Schans C, Prasad A, Main E. Chest physiotherapy compared to no chest physiotherapy for cystic fibrosis. The Cochrane Database of Systematic Reviews 2003; 3: http:/ / 80-gateway1.ovid.com.opac.library.usyd.edu.au/ovidweb. cgi. Last accessed: November 2, 2004.

8 Hasani A, Pavia D, Agnew JE, Clarke SW. Regional clearance during cough and forced expiration technique (FET): effects of flow and viscoelasticity. Thorax 1994; 49: 557-561.

9 Oldenburg FA Jr, Dolovich MB, Montgomery JM, Newhouse MT. Effects of postural drainage, exercise and cough on mucus clearance in chronic bronchitis. Am Rev Respir Dis 1979; 120: 739-745.

10 van der Schans CP, Piers DA, Beekhuis H, Koëter GH, van der Mark TW, Postma DS. Effect of forced expirations on mucus clearance in patients with chronic airflow limitation: effect of lung recoil pressure. Thorax 1990; 45: 623-627.

11 Mortensen J, Falk M, Groth S, Jensen C. The effects of postural drainage and positive expiratory pressure on tracheobronchial clearance in cystic fibrosis. Chest 1991; 100: 1350-1357.
12 Volsko TA, DiFiore JM, Chatburn RL. Performance comparison of two oscillating expiratory pressure devices: Acapella versus Flutter. Respir Care 2003; 48: 124-130.

13 Gross D, Zidulka A, O’Brien C, et al. Peripheral mucociliary clearance with high-frequency chest wall compression. J Appl Physiol 1985; 58: 1157-1163.

14 Maxwell L, Crosbie J, Ellis ER. A new system for examining pattern of ventilation. Aust J Physiother 2001; 147: 271.

15 ATS/ERS Taskforce. Standardisation of spirometry. Eur Respir J 2005; 26: 319-338.

16 Wilson RC, Jones PW. Long term reproducibility of Borg scale estimates of breathlessness during exercise. Clin Sc 1991; 80: 309-312.

17 Winter DA, Patla AE. Signal Processing and Linear Systems for the Movement Sciences. Ontario, Waterloo Biomechanics, 1997; pp. 51-76.

18 Cystic Fibrosis Australia. Cystic Fibrosis in Australia and New Zealand 2001. Annual report from the Australasia Cystic Fibrosis Data Registry. Ryde, Cystic Fibrosis Australia, 2003; pp. 20-22, 43-44.

19 Kim CS, Greene MA, Sankaran S, Sackner MA. Mucus transport in the airways by two-phase gas-liquid flow mechanism: continuous flow model. J Appl Physiol 1986; 60: 908-917.

20 Kim CS, Rodriguez CR, Eldridge MA, Sackner MA. Criteria for mucus transport in the airways by two-phase gas-liquid flow mechanism. I Appl Physiol 1986; 60: 901-907.

21 Sackner MA, Kim CS. Phasic flow mechanisms of mucus clearance. Eur J Respir Dis 1987; 71: Suppl. 153, 159-164.

22 Oberwaldner B, Evans JC, Zach MS. Forced expirations against a variable resistance: a new chest physiotherapy method in cystic fibrosis. Ped Pulm 1986; 2: 358-367.

23 Menkes HA, Traystman RJ. Collateral ventilation. Am Rev Respir Dis 1977; 116: 287-309.

24 Sanderson MJ, Chow I, Dirkson ER. Intercellular communication between ciliated cells in culture. Am J Physiol 1988; 254: C63-C74.

25 Sanderson MJ, Charles AC, Dirksen ER. Mechanical stimulation and intercellular communication increases intracellular Ca2+ in epithelial cells. Cell Regul 1990; 1: 585-596.

26 Langlands J. The dynamics in cough in health and in chronic bronchitis. Thorax 1967; 22: 88-96.

27 Louden RG, Shaw GB. Mechanics of cough in normal subjects and in patients with obstructive respiratory disease. Am Rev Respir Dis 1967; 96: 666-677. 